\title{
Definitive carbon ion radiotherapy for tracheobronchial adenoid cystic carcinoma: a preliminary report
}

\author{
Jian Chen ${ }^{1,2}$, Jingfang Mao ${ }^{2,3^{*}}$, Ningyi Ma ${ }^{1,2}$, Kai-Liang $\mathrm{Wu}^{2,3}$, Jiade $\mathrm{Lu}^{1,2}$ and Guo-Liang Jiang ${ }^{2,3}$
}

\begin{abstract}
Background: Tracheobronchial adenoid cystic carcinoma (TACC) is a rare tumour. About one-third of patients miss their chance of surgery or complete resection as it is mostly detected in the advanced stage; hence, photon radiotherapy (RT) is used. However, the outcomes of photon RT remain unsatisfactory. Carbon ion radiotherapy (CIRT) is thought to improve the therapeutic gain ratio; however, the outcomes of CIRT in TACC are unclear. Therefore, we aimed to assess the effects and toxicities of CIRT in patients with TACC.

Methods: The inclusion criteria were as follows: 1) age 18-80 years; 2) Eastern Cooperative Oncology Group Performance Status 0-2; 3) histologically confirmed TACC; 4) stage III-IV disease; 5) visible primary tumour; and 6) no previous RT history. The planned prescription doses of CIRT were 66-72.6 GyE/22-23 fractions. The rates of overall survival (OS), local control (LC), and progression-free survival (PFS) were calculated using the Kaplan-Meier method. Treatment-induced toxicities and tumour response were scored according to the Common Terminology Criteria for Adverse Events and Response Evaluation Criteria in Solid Tumors, respectively.
\end{abstract}

Results: Eighteen patients with a median age of 48 (range 30-73) years were enrolled. The median follow-up time was 20.7 (range 5.8-44.1) months. The overall response rate was $88.2 \%$. Five patients developed lung metastasis after 12.2-41.0 months and one of them experienced local recurrence at 31.9 months after CIRT. The rates of 2-year OS, LC, and PFS were 100, 100, and 61.4\%, respectively. Except for one patient who experienced grade 4 tracheal stenosis, which was relieved after stent implantation, no other $\geq 3$ grade toxicities were observed.

Conclusions: CIRT might be safe and effective in the management of TACC based on a short observation period. Further studies with more cases and longer observation are warranted.

Keywords: Tracheobronchial carcinoma, Adenoid cystic carcinoma, Carbon ion radiotherapy

\section{Background}

Salivary gland tumours are rare diseases that could affect head, neck, breast, pelvis, gynaecological tract, and trachea [1-6]. Twenty-two percent of malignant salivary

\footnotetext{
* Correspondence: jingfang.mao@sphic.org.cn

${ }^{2}$ Shanghai Key Laboratory of Radiation Oncology, Shanghai Engineering Research Center of Proton and Heavy Ion Radiation Therapy, Shanghai 201321, China

${ }^{3}$ Department of Radiation Oncology, Shanghai Proton and Heavy lon Center, Fudan University Cancer Hospital, Shanghai 201321, China

Full list of author information is available at the end of the article
}

gland tumours are adenoid cystic carcinomas (ACCs). Tracheobronchial adenoid cystic carcinoma (TACC) originates from the submucosal glands of the tracheobronchial tree, and accounts for only $10 \%$ of tracheal tumours. The incidence of primary tracheal tumours is < 0.2 per 100,000 persons per year in the United States [7-10]. TACC grows slowly, is mostly asymptomatic in the early stage, and is often discovered at an advanced stage [11]. Surgical resection plays an important role in treatment. However, by the time of diagnosis, about

C C The Author(s). 2021 Open Access This article is licensed under a Creative Commons Attribution 4.0 International License, which permits use, sharing, adaptation, distribution and reproduction in any medium or format, as long as you give appropriate credit to the original author(s) and the source, provide a link to the Creative Commons licence, and indicate if changes were made. The images or other third party material in this article are included in the article's Creative Commons licence, unless indicated otherwise in a credit line to the material. If material is not included in the article's Creative Commons licence and your intended use is not permitted by statutory regulation or exceeds the permitted use, you will need to obtain permission directly from the copyright holder. To view a copy of this licence, visit http://creativecommons.org/licenses/by/4.0/ The Creative Commons Public Domain Dedication waiver (http://creativecommons.org/publicdomain/zero/1.0/) applies to the data made available in this article, unless otherwise stated in a credit line to the data. 
one-third of patients have missed their chance of surgery or complete resection due to the limited resection scope of the trachea and the tumour's characteristic spread along the bronchial wall and/or nerves at an early stage [12]. It has been reported that a positive surgical margin (R1 or R2 resection) after surgery could occur in 50\% [13]-84.4\% [14] of all cases.

X-ray radiation therapy (RT), as an adjuvant or definitive treatment method, has been used for TACC. In the early years, the clinical outcomes of definitive RT for TACC were not satisfactory as it is a slowly-growing malignancy and resistant to RT [9, 15-17]. Modern RT techniques such as intensity-modulated radiation therapy (IMRT) have provided improved results [13, 18]. As TACC is a very rare disease, no prospective study on it has been conducted. Only a few retrospective studies have been published to date, and less than 300 TACC patients receiving definitive RT have been reported [11-13, 1525]. Therefore, the exact role of RT remains unclear.

Charged particle beams, including proton and carbon ion beams, have physical advantages, such as specific dose distribution of the Bragg peak and narrow penumbra. Therefore, they could provide better sparing of normal tissue [26-28]. In addition, carbon ions are characterized by high linear energy transfer (LET), and thus, carbon ion beam produces a stronger biological effect in killing tumour cells with high relative biological effect (RBE), especially for radio-resistant tumours [29, 30]. The synergy of these two features provides a critical advantage in radio-resistant malignancies. In head and neck ACC, Jensen et al. [31] found that photon plus carbon ion radiotherapy (CIRT) boost could improve local control (LC) and survival when compared to photon therapy only. Högerle et al. [13] reported on 38 TACC patients treated with surgery and/or radiotherapy with either CIRT or photons. The 5-year overall survival (OS), freedom from local progression, and freedom from distant progression in patients who underwent RT alone and multimodal treatment including surgery and adjuvant RT were 100 and $84 \%, 88$ and $100 \%$, and 67 and $65 \%$, respectively. Two patients received CIRT only, one for adjuvant therapy and another for definitive therapy. A high LC rate was achieved 20 months after CIRT.

Our centre, Shanghai Proton and Heavy Ion Center (SPHIC) was officially opened in 2015. Since then, we have treated 23 patients having TACC with CIRT. Here, we retrospectively summarize the preliminary results.

\section{Methods}

\section{Patients and pretreatment evaluations}

Patients who met the following criteria were enrolled onto in this study: 1) $18-80$ years old; 2) Eastern Cooperative Oncology Group Performance Status 0-2; 3) histologically confirmed TACC; 4) stage III-IV disease according to the modified Bhattacharyya's protocol [13]; 5) visible primary tumour; and 6) no previous RT history. The study was approved by the IRB of SPHIC (approval number SPHIC-TR-2017-02, RS). Informed consent was obtained from all the participants.

Pretreatment evaluation in all patients included complete disease history and physical examination, complete blood count, serum electrolytes, renal and liver function tests, electrocardiogram, pulmonary function tests, and a mandatory fluorodeoxyglucose positron emission tomography/computed tomography (FDG$\mathrm{PET} / \mathrm{CT}$ ) scan for clinical staging, same as pretreatment evaluation for lung cancer patients we reported before [32]. Bronchoscopy was required for all patients. For patients whose esophagus was suspiciously invaded by tumour, ultrasound esophagoscopy/gastroscopy was mandatory before CIRT.

\section{Preparing, planning and delivery of CIRT}

The procedures of CIRT, including preparing, planning and delivery, was performed similar to previously described [32]. The patients were immobilized in the supine position using thermoplastic masks with either an AlphaCradle $^{\circ}$ (for lesions located in the upper part of the trachea) or a vacuum bag (for lesions located in the lower part of the trachea or bronchus) to immobilize the patient's body position and restrict the breath motion for patients using free breathing $(\mathrm{FB})$ or gating.

The scanning scope of the simulation computer tomography $(\mathrm{CT})$ starts from the angle of the mandible to the adrenal glands to include tumour lesions, entire lungs, whole neck, and all the organs/tissues through which the beams were likely to pass. All patients were evaluated for tumour motion using 4-dimensional (4-D) simulation CT. If the tumour motion in any direction was less than $5 \mathrm{~mm}$, the patient was treated under $\mathrm{FB}$; if the motion exceeded $5 \mathrm{~mm}$, a breath control technique, either active breathing control (ABC, Elekta Oncology Systems, Crawley, UK) or respiratory gating (Anzai Respiratory Gating System, AZ-733 V, Anzai Medical Co. Ltd., Japan), was required to mitigate the residual motion (RM) to $<5 \mathrm{~mm}$ during treatment. For patients using gating, 10 phases of the whole respiratory cycle were reconstructed on 4-D CT. The gating window (respiratory phase time when the beam is on, usually around the end of exhalation) was selected to restrict the RM to $<5 \mathrm{~mm}$, same as breath control methods for lung cancer patients we reported before [32].

The target delineation was also similar as our protocol for lung cancer patients [32]. Gross tumour volume (GTV) was determined according to contrast thoracic $\mathrm{CT}$ and PET/CT or magnetic resonance imaging (MRI). For patients using the gating technique, an internal gross tumour volume (iGTV) was created by combining the 
GTVs of all respiratory phases. The clinical target volume (CTV) was defined as a $0.5-1.0 \mathrm{~cm}$ expansion in the circumferential direction and a $1.0-2.0 \mathrm{~cm}(2.0 \mathrm{~cm}$ in 15 of 18 patients) margin in the longitudinal direction. Range uncertainties and set-up errors were taken into account when creating the planning target volume (PTV). In most instances, it was CTV plus a $0.3-0.5 \mathrm{~cm}$ lateral margin and a $0.5-1.2 \mathrm{~cm}$ margin along the beam direction. The dose of CIRT was defined as the equivalent dose to Gy of photon (GyE). The relative biological effective dose was calculated based on the local effect model I, with typical RBEs within the spread out bragg peak (SOBPs) of about $3.0 \sim 5.0$ [33]. The prescription doses were $66-72.6 \mathrm{GyE}$ in $22-23$ fractions, 5 fractions a week. A metastatic lesion in one patient's right lower lobe detected before CIRT was treated using stereotactic body radiotherapy (SBRT) with a total dose of $60 \mathrm{~Gy}$ in 10 fractions, 5 fractions a week.

The target coverage requirements were as follows: (i) at least $99 \%$ of the GTV was covered by $99 \%$ of the prescription dose, (ii) $99 \%$ of the CTV by $95 \%$ of the prescription dose, and (iii) $90 \%$ of the PTV by $90 \%$ of the prescription dose. The dose constraints for the main organs at risk (OARs) included: (1) lung: mean dose (Dmean) of bilateral lungs < 15 GyE, the percentage volume of the lung receiving $20 \mathrm{GyE}$ or more in total lung (V20) $<20 \%$, V5 $<50 \%$; maximum dose (Dmax) of the main bronchial tree $<105 \%$ of the prescription dose; (2) heart: V30<30\%, V40<25\%; (3) oesophagus: Dmean <34 GyE, Dmax $<105 \%$ of the prescription dose; (4) spinal cord: Dmax $<45 \mathrm{GyE}$; (5) thyroid: Dmean < $45 \mathrm{GyE}$; and (6) stomach: Dmax < 45 GyE.

The Siemens Syngo Planning System ${ }^{\circ}$ was used for planning in all patients. Beam energy $85-430 \mathrm{MeV}$ (CIRT) plans were designed using $2-4$ beams with the PBS technique. Two orthogonal X-ray images were taken to verify the patient's position according to bone structures before each daily irradiation. A set-up error $\leq$ $3 \mathrm{~mm}$ before the treatment was allowed. Carbon ion beams were delivered under the same breath control mode used for simulation CT. All the patients underwent review $\mathrm{CT}$ before the first treatment and every week during treatment, and plan recalculation on the latest CT was conducted for every patient to check the dose distribution. Replanning was demanded when recalculation revealed poor coverage of targets or overdosing to the organs at risk. These procedures were same as treatment protocols for lung cancer patients we treated before [32].

\section{Follow-up and evaluation}

This part was similar to previously described [32]. All patients were evaluated weekly for treatment-induced toxicities and disease response/progression during treatment. If the patient had any symptoms or signs of airway stenosis or disease recurrence, bronchoscopy was strongly recommended. After the completion of CIRT, all patients were required to be evaluated 3 months after the 1st day of CIRT, every 3-4 months within the first 2 years, every 6 months between years 3 and 5 , and annually thereafter. Treatment-induced side effects were scored according to the Common Terminology Criteria for Adverse Events, version 4.03. Toxicities occurring 90 or more days after the initiation of CIRT were defined as late toxicities. The Response Evaluation Criteria in Solid Tumors, version 1.1, was used for tumour response evaluation.

\section{Statistical analyses}

The objective response rate (ORR) was defined as the proportion of patients who reached complete response (CR) or partial response (PR) and kept for more than 3 months in all patients. The rates of overall survival (OS), local control (LC), and progression free survival (PFS) were calculated using the Kaplan-Meier method. The times to events were calculated from the start of CIRT until the first documented treatment failure. OS was defined till the date of death or the last follow-up. LC was defined till the date of local failure or the last follow-up. PFS was defined till the date of disease progression at any site or death, or the last follow up. All analyses were performed using SPSS $^{\bullet}$ statistics version 26 (Armonk, NY, USA).

\section{Results}

\section{Patient characteristics}

From March 2016 to December 2019, 23 consecutive patients with TACC received CIRT in the SPHIC. Among them, three patients previously received RT; two treated by radical surgery with positive surgical margins but had no visible residual tumour (R1 resection). Hence, 18 patients who met the inclusion criteria were enrolled in this analysis. Five patients were treatment-naive, two underwent R2 resection, one underwent exploratory surgery, three had recurrent tumour 1.2-30 years after surgery, and seven underwent endoscopic debulking surgery (including argon helium laser ablation, cryosurgical ablation, and endoscopic trepanned resection) before CIRT. One patient had one lung metastatic lesion and one had multiple lung metastases before CIRT. The lesions in six patients involved the carina or bilateral main bronchus. Thirteen patients had lesions that were longer than $5 \mathrm{~cm}$. Patient characteristics are detailed in Table 1. 
Table 1 Characteristics of patients and treatment

\begin{tabular}{|c|c|}
\hline Characteristic & Value \\
\hline No. of patients & 18 \\
\hline \multicolumn{2}{|c|}{ Age at treatment, y } \\
\hline Median & 48.0 \\
\hline Range & $30-73$ \\
\hline \multicolumn{2}{|l|}{ Sex } \\
\hline Male & 10 \\
\hline Female & 8 \\
\hline \multicolumn{2}{|l|}{ ECOG score } \\
\hline 0 & 14 \\
\hline 1 & 4 \\
\hline \multicolumn{2}{|l|}{ Smoking history } \\
\hline Yes & 5 \\
\hline No & 13 \\
\hline \multicolumn{2}{|c|}{ Diameter on transversal section, $\mathrm{mm}$} \\
\hline Median & 34.0 \\
\hline Range & $19.0-54.0$ \\
\hline \multicolumn{2}{|c|}{ Length on craniocaudal direction, $\mathrm{mm}$} \\
\hline Median & 61.5 \\
\hline Range & $27.0-109.0$ \\
\hline \multicolumn{2}{|c|}{ GTV Volume, $\mathrm{cm}^{3}$} \\
\hline Median & 42.675 \\
\hline Range & $5.61-87.51$ \\
\hline \multicolumn{2}{|l|}{ Stage $e^{a}$ : } \\
\hline III & 7 \\
\hline T3NOMO & 7 \\
\hline IV & 11 \\
\hline T1N1M0 & 1 \\
\hline T3N1M0 & 3 \\
\hline T4NOMO & 5 \\
\hline $\mathrm{T} 4 \mathrm{NOM} 1^{\mathrm{b}}$ & 2 \\
\hline \multicolumn{2}{|l|}{ Chemotherapy } \\
\hline Yes & 2 \\
\hline No & 16 \\
\hline
\end{tabular}

Carbon ion radiotherapy

66 GyE / 22 fractions

69 GyE / 23 fractions 10

72.6 GyE / 22 fractions 5

82.5-85.8 GyE / 25-26 fractions

ECOG Eastern Cooperative Oncology Group, GTV gross tumor volume a Modified Bhattacharyya staging system [13].

${ }^{\mathrm{b}}$ One patient had one solid lung metastatic lesion, and one patient had multiple lung metastases before carbon ion radiotherapy
CIRT

Among 18 patients, the methods used for breathing control were $A B C$ in 1 patient, respiratory gating in 9 patients, and FB in 8 patients.

Sixteen patients received a total dose of 66-72.6 GyE/ 22-23 fractions (Table 1). The two patients who received more than 72.6 GyE experienced treatment interruptions of 25 days and 2 months due to infectious pneumonia and whole lung atelectasis by mucosal oedema in the extremely narrowed bronchus after surgery, respectively. The compensated dose was decided by the physician's discretion after balancing tumour cell re-proliferation and the protection of OARs.

\section{Toxicities}

All patients tolerated CIRT well. No patient experienced grade 3 or higher acute toxicities. Grade 2 acute toxicities included oesophagitis (two cases), pneumonitis (one), tracheal stenosis (one), hoarseness (one), and haematological toxicities (one). Regarding late toxicities, airway stenosis was observed in three patients. Among them, one patient who underwent argon helium laser ablation plus cryosurgical ablation before CIRT experienced grade 4 tracheal stenosis 4.5 months from the first fraction of CIRT, and the stenosis was relieved after stent insertion. The second patient received similar endoscopic debulking treatment before RT and developed grade 2 tracheal stenosis 1.2 months from the first fraction of CIRT, and symptoms improved after symptomatic treatment. The third patient, whose lesion was located close to the glottis, experienced grade 2 laryngostenosis 8 months after the first fraction of CIRT, and the symptoms were relieved after symptomatic therapy. The median maximal doses to the trachea/larynx of patients with or without airway stenosis were $72.91 \mathrm{GyE}$ (range 68.69 73.19) versus $72.66 \mathrm{GyE}$ (range: 69.73 $87.41)$. Other grade 2 late toxicities included radiationinduced lung injury (RILI) (three cases), hypothyroidism (one), and tracheitis (one) (Tables 2 and 3).

Table 2 Acute toxicities of the entire cohort

\begin{tabular}{llll}
\hline Acute toxicity & \multicolumn{4}{l}{ Grade (percentage, \%) } \\
\cline { 2 - 4 } & $\mathbf{1}$ & $\mathbf{2}$ & $\mathbf{3} \mathbf{5}$ \\
\hline Esophagitis & $12(66.7)$ & $2(11.1)$ & $0(0.0)$ \\
Pneumonitis & $3(16.7)$ & $1(5.6)$ & $0(0.0)$ \\
Neutropenia & $3(16.7)$ & $1(5.6)$ & $0(0.0)$ \\
Hoarseness & $2(11.1)$ & $1(5.6)$ & $0(0.0)$ \\
Tracheal stenosis & $0(0.0)$ & $1(5.6)$ & $0(0.0)$ \\
Dermatitis & $6(33.3)$ & $0(0.0)$ & $0(0.0)$ \\
Cough & $6(33.3)$ & $0(0.0)$ & $0(0.0)$ \\
Leukocytopenia & $6(33.3)$ & $0(0.0)$ & $0(0.0)$ \\
Anemia & $1(5.6)$ & $0(0.0)$ & $0(0.0)$ \\
\hline
\end{tabular}


Table 3 Late toxicities of the entire cohort

\begin{tabular}{|c|c|c|c|c|c|}
\hline \multirow[t]{2}{*}{ Late toxicity } & \multirow[b]{2}{*}{1} & \multicolumn{3}{|c|}{ Grade (percentage, \%) } & \multirow[b]{2}{*}{5} \\
\hline & & 2 & 3 & 4 & \\
\hline Tracheal stenosis & $0(0.0)$ & $1(5.6)$ & $0(0.0)$ & $1(5.6)$ & $0(0.0)$ \\
\hline RILI & $5(27.8)$ & $3(16.7)$ & $0(0.0)$ & $0(0.0)$ & $0(0.0)$ \\
\hline Tracheitis & $0(0.0)$ & $1(5.6)$ & $0(0.0)$ & $0(0.0)$ & $0(0.0)$ \\
\hline Laryngostenosis & $0(0.0)$ & $1(5.6)$ & $0(0.0)$ & $0(0.0)$ & $0(0.0)$ \\
\hline Hypothyroidism & $0(0.0)$ & $1(5.6)$ & $0(0.0)$ & $0(0.0)$ & $0(0.0)$ \\
\hline Pleural effusion & $2(11.1)$ & $0(0.0)$ & $0(0.0)$ & $0(0.0)$ & $0(0.0)$ \\
\hline Skin & $1(5.6)$ & $0(0.0)$ & $0(0.0)$ & $0(0.0)$ & $0(0.0)$ \\
\hline
\end{tabular}

RILI radiation-induced lung injury

\section{Clinical outcomes}

On June 30, 2020, the median follow-up time was 20.7 (range 5.8-44.1) months. Tumour response at 3 months after CIRT was evaluated in 17 patients, except for 1 patient, whose tumour was not shown clearly on CT due to the atelectasis. ORR was $88.2 \%$ with $\mathrm{CR}$ in 7 , PR in 8 , and stable disease (SD) in 2 patients. Five distant metastases occurred in five patients during follow-up. Among them, one patient with stage IV (T4NOM0) disease developed multiple lung metastases after 14.8 months and experienced local recurrence 31.9 months from the first fraction of CIRT with a dose of $69 \mathrm{GyE} / 23$ fractions. One or more newly emerged metastatic lung lesions were observed in the other four patients 12.2-41.0 months from the first fraction of CIRT. For salvage treatments, one patient received radioactive seed implantation for local recurrence, and one SBRT for lung metastases. The median PFS time in all patients was 41.0 (95\% confidence interval [CI], 9.3-72.7) months. The rates of 2-year OS, LC, and PFS were 100, 100, and $61.4 \%$, respectively, for the whole cohort. A typical case is shown in Fig. 1. The 2-year LC and PFS are shown in Fig. 2.

\section{Discussion}

TACC is a very rare tumour, and the clinical experience is limited. Although surgery plays the most critical role, radical resection is often difficult. RT has not been recognized for its role in the management of TACC. Published data on radical or definitive RT for TACC patients have been limited to small sample sizes.

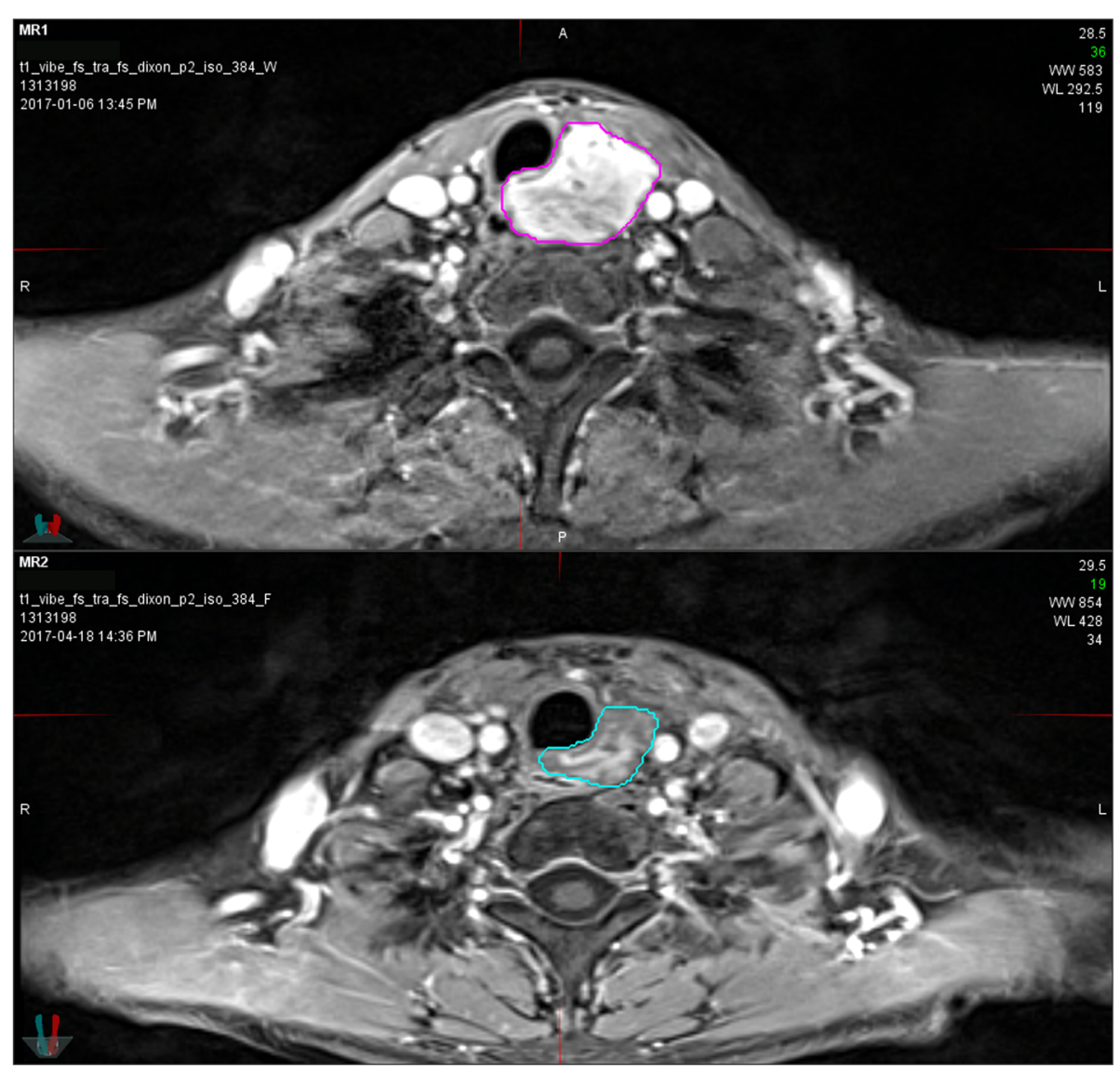

Fig. 1 A typical case. A typical case of tracheal adenoid cystic carcinoma located in the upper third portion of the trachea. The patient was treated with carbon ion radiotherapy of $69 \mathrm{GyE}$ in 23 fractions. The tumour shrank significantly 3 months after carbon ion radiotherapy and was evaluated as partial response 

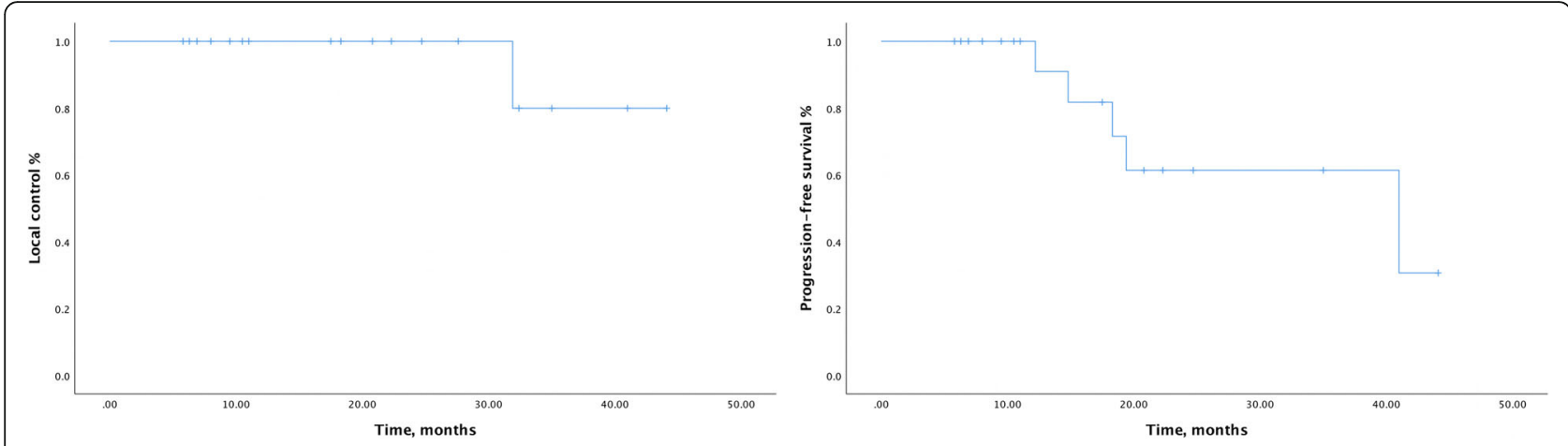

Fig. 2 Local control and progression-free survival. Local control (LC) and progression-free survival (PFS) after carbon ion radiotherapy in 18 patients

Compared to surgery with or without adjuvant RT, definitive RT usually resulted in inferior clinical outcomes in several retrospective analyses (see Table 4). In reports published before 2012, the 5-year OS rates varied from 40 to $53 \%$ [9, 15-17]. More recently, definitive RT was reported to have improved outcomes in some studies with small sample sizes, with a 5-year OS of $63.7-86 \%$ $[11,18,24]$. The 5 -year LC rates reached $90-100 \%$ as reported by Je et al. and Levy et al. in only 9 patients each $[11,18]$.

Regarding the application of particle RT (neutron, proton, and heavy ion beams) in TACC, a few studies have been published. Bittner et al. [22] reported 2-year LC and OS rates of 89 and $89.4 \%$, respectively, in 20 patients, when using neutrons. There were two cases of grade 3/4 chronic toxicities, including one case of tracheal stenosis and one of brachial plexopathy. Neutron

Table 4 Outcomes of surgery with/without postoperative radiotherapy and radiotherapy only for tracheobronchial adenoid cystic

\begin{tabular}{|c|c|c|c|c|c|c|c|c|}
\hline Author & Year & Case number & Therapy & MST (month) & 5-y LC (\%) & 5-y OS (\%) & 10-y LC (\%) & $10-y$ OS (\%) \\
\hline \multirow[t]{2}{*}{ Grill [19] } & 1990 & 45 & $S+R$ & 118 & & & & \\
\hline & & 12 & $\mathrm{R}$ & 28 & & & & \\
\hline \multirow[t]{2}{*}{ Maziak [20] } & 1996 & 36 & $S+/-R$ & 87 & & & & \\
\hline & & 6 & R & 73 & & & & \\
\hline \multirow[t]{2}{*}{ Kanematsu [16] } & 2002 & 11 & $S+/-R$ & & & 91 & & 76 \\
\hline & & 5 & $\mathrm{R}$ & & & 40 & & 0 \\
\hline \multirow[t]{2}{*}{ Molina [9] } & 2007 & 24 & $S+/-R$ & & & 70 & & 63 \\
\hline & & 16 & $\mathrm{R}$ & & & 53 & & 31 \\
\hline \multirow[t]{2}{*}{ Lee $[17]$} & 2011 & 17 & $S+/-R$ & & & 100 & & 90 \\
\hline & & 13 & $R+/-C$ & & & 54 & & 27 \\
\hline \multirow[t]{2}{*}{ Shadmehr [15] } & 2011 & 13 & $S+R$ & 68.8 & & 78 & & \\
\hline & & 5 & $R$ & 21.2 & & $40(2-y)$ & & \\
\hline \multirow[t]{2}{*}{ Je [18] } & 2017 & 13 & $S+R$ & & 100 & 92.3 & 100 & 76.9 \\
\hline & & 9 & $\mathrm{R}$ & & 100 & 66.7 & 26.7 & 22.2 \\
\hline \multirow[t]{2}{*}{ Levy [11] } & 2018 & 22 & $S+R$ & & 100 & 82 & & \\
\hline & & 9 & $\mathrm{R}$ & & 90 & 86 & & \\
\hline \multirow[t]{3}{*}{ Högerle [13] } & 2019 & 7 & s & & 100 & 100 & 100 & 80 \\
\hline & & 13 & $S+R$ & & 100 & 92 & 100 & 82 \\
\hline & & 18 & R & & 86 & 100 & 43 & 83 \\
\hline \multirow[t]{2}{*}{ Wang [24] } & 2019 & 156 & $S+/-R$ & 198 & & 85 & & 63.4 \\
\hline & & 27 & $\mathrm{R}$ & 92 & & 63.7 & & 46.4 \\
\hline
\end{tabular}


RT has been abandoned globally in RT society because of severe toxicity. Verma et al. [25] reported results of proton RT in five TACC patients. With a median follow-up of 10 months, no recurrent disease was observed. One patient developed bronchial stenosis and required a stent. The study conducted by Högerle et al. was the only one, which used CIRT to treat TACC; however, only two patients were treated with CIRT alone, and another five were treated with combined photon and carbon ion therapy [13]. It is therefore, difficult to determine the efficacy and toxicities of CIRT in TACC patients with such a small sample.

TACC is thought to be a slowly growing malignancy and with radio-resistance. CIRT has been demonstrated to have biological advantages on radio-resistant malignancies in in-vitro and in-vivo experiments, as well as in clinical practice [34]. Its capability to sterilize malignancies is 2-3 times stronger than that of a conventional Xray RT with RBE of 2-3, especially for radio-resistant tumours [29]. Apart from the biological advantage, CIRT also has advantages such as dose distributions of Bragg peak, which could spare normal structures around the targets significantly [26]. In the current study, we have successfully delivered CIRT of 69-72.6 GyE in 15 out of all 18 TACC patients. Overall, the acute and late toxicities were mild. Only one patient experienced grade 4 tracheal stenosis. The maximal doses to the trachea/larynx were similar between patients with and without airway stenosis of any grade. Fisher's exact test showed the rate of stenosis occurrence was not different between patients received intra-tracheal ablation and those did not $(p=0.528)$. Whether the stenosis was caused by the intra-tracheal laser ablation, the nature of an intraluminal malignancy, or individual radiation sensitivity of trachea, etc. remains unclear and need to be further investigated. No other grade $\geq 3$ adverse effects were observed. The 2-year LC and OS rates for the whole cohort reached $100 \%$ with a median follow-up time of 20.7 months. Only one patient developed local recurrence at 31.9 months from the first fraction of CIRT and, including this patient, five had distant metastatic (DM) lesions to the lungs. Our results using CIRT are promising compared to those using photon or neutron beams.

There are currently no up to date guidelines on the CIRT technique that we could follow. TACC tends to have mucosal or sub-mucosal spread along the tracheal wall; the subclinical lesion is at least $1 \mathrm{~cm}$ beyond the visible or palpable tumours [35]. To cover the subclinical lesion, some authors used a $3-\mathrm{cm}$ margin beyond the GTV to create the CTV $[18,24]$. In this study, the CTV was defined in most cases as the GTV plus margins of 2 $\mathrm{cm}$ longitudinally and $0.5-1 \mathrm{~cm}$ circumferentially. At the last follow-up, no marginal recurrences were observed. Additionally, as the regional lymph node involvement rate was low, and given that lymph node involvement has little impact on prognosis, [19] prophylactic lymph node drainage area irradiation was not recommended. In this study, elective nodal irradiation was not applied, and no regional lymph node recurrence was observed. These results suggest the suitability of the radiation field design of this study; and the same strategy has been implemented in our phase II prospective study for TACC. Without guidelines, we were also unsure of the exact dose and fractionation to be delivered. From the literature, doses as high as 56-60 Gy were needed for X-ray RT $[21,36]$. In some studies, brachytherapy was used to increase the dose to as high as $74.4 \mathrm{~Gy}$, and the 5-year LC rate reached $100 \%[13,18]$. However, endobronchial brachytherapy was associated with higher fatal haemoptysis, ulcers, necrosis, or stenosis of the bronchi as late severe respiratory complications. Furthermore, brachytherapy was not suitable in patients with extrabronchial spread or regional lymph node metastasis [37-39]. In this study, 66-72.6 GyE/22-23 Fx of carbon ion doses were used and a 100\% 2-year LC was achieved with mild toxicities. The dose seemed effective and well tolerated, and CIRT could provide higher tumour control probability (TCP) without significantly increasing the normal tissue complication probability (NTCP).

In this study, the most prominent late toxicity was airway stenosis, which can be life threatening. Airway stenosis was observed in other published reports, using either surgery or radiation therapy, and the incidence varied from 5 to $23 \%$ [11, 18, 22, 25]. In our study, 3 of 18 patients $(17 \%)$ developed tracheal stenosis with Grade 4 in 1 and Grade 2 in 2. Two of 3 received intra-tracheal surgery or laser ablation before CIRT, which most likely attributed to the stenosis, and the third one had a lesion in his glottis. One patient developed entire right lung atelectasis during CIRT, and the cause of it was likely the prior surgery, which involved the right main bronchi. As TACC originates from the tracheal epithelium, it is easy to develop airway stenosis, especially in patients undergoing prior surgery or ablation. Therefore, we should always be aware of this risk, and adopt necessary preventive measurements.

Lung metastasis was an important outcome in the patients in this study. Five developed new metastases to the lungs after CIRT; the 2-year DM rate was $38.6 \%$. This is consistent with previous reports that the 5 -year lung metastasis rate could be as high as $77.8 \%$ (20$77.8 \%)[11,13,18]$. The development of systemic treatment seems to be important. However, chemotherapy provided very limited benefit for ACC patients with lung metastases, [40] and an effective target therapy is still under development. A phase II study showed that lenvatinib had an ORR of $15.6 \%$ for recurrent TACC, while 18 of 32 patients discontinued therapy because of drug- 
related issues [41]. Therefore, it is a great challenge to develop new medications to further improve TACC outcomes.

There were some limitations to this study. First, the number of patients was small. Second, the compensated dose for interruptions of CIRT was decided by the physician's discretion as there was no established compensation method and dose constraints to OARs for CIRT to follow. Third, the follow-up time was not long enough, especially for this slowly growing tumour, and thus, local control and survival rates may have not reached their final values. Prospective studies with large sample sizes are warranted to better define the role of CIRT in patients with TACC. Two prospective phase II clinical trials involving patients with different surgical statuses are ongoing in our centre.

\section{Conclusions}

To the best of our knowledge, this is the first report on TACC treated only by CIRT for all the patients. This study showed that CIRT was feasible; toxicities were mild, and overall survival and local control at 2-years were satisfactory. However, more patients and long-term follow-up are needed to confirm the findings shown in this study.

\section{Acknowledgments}

The authors would like to acknowledge the assistance of the staff at the Department of Medical Physics at the Shanghai Proton and Heavy Ion Center.

\begin{abstract}
Authors' contributions
JM participated in study design, data interpretation, reviewing and editing of the manuscript, funding acquisition and acts as guarantor of this entire manuscript. JC participated in data analysis, writing of manuscript and funding acquisition. NM participated in investigation and funding acquisition. KLW participated in reviewing and editing of the manuscript. $J$ participated in reviewing and editing of the manuscript. G- $\sqcup J$ participated in reviewing and editing of the manuscript and funding acquisition. All authors reviewed and approved the manuscript.
\end{abstract}

\section{Funding}

The study was supported by grant funds from Shanghai Shen Kang Hospital Development Center New Frontier Technology Joint Project of Municipal Hospital [grant number SHDC12017114], Shanghai Science and Technology Development Funds [grant number 18ZR1436300], Shanghai Municipal Health Commission Funds [grant number 201840155], Shanghai Key Laboratory of radiation oncology Funds [grant number 20dz2261000], Shanghai Pudong New Area Science and Technology Development Fund for the People's Livelihood Research Project [grant number PKJ2017-Y52 and PKJ2018-Y48], and Shanghai Science and Technology Development Funds [grant number 15411950103]. The funding source has no involvement in study design, collection, analysis and interpretation of data, the writing of the report or the decision to submit the article for publication.

\section{Availability of data and materials}

The datasets used in the current study available from the corresponding author on reasonable request.

\section{Declarations}

\section{Ethics approval and consent to participate}

The research received approval of the Shanghai Proton and Heavy lon Center (SPHIC) Institutional Research Board (IRB). Informed consent was obtained from all the participants. All methods were performed in accordance with the relevant guidelines and regulations.

\section{Consent for publication}

Not applicable.

\section{Competing interests}

None.

\section{Author details}

'Department of Radiation Oncology, Shanghai Proton and Heavy lon Center, Shanghai 201321, China. 'Shanghai Key Laboratory of Radiation Oncology, Shanghai Engineering Research Center of Proton and Heavy lon Radiation Therapy, Shanghai 201321, China. ${ }^{3}$ Department of Radiation Oncology, Shanghai Proton and Heavy Ion Center, Fudan University Cancer Hospital, Shanghai 201321, China.

Received: 1 February 2021 Accepted: 7 June 2021

Published online: 26 June 2021

References

1. Moran CA. Primary salivary gland-type tumors of the lung. Semin Diagn Pathol. 1995;12(2):106-22.

2. Pearson F, CP, Keshavjee S. Primary tumours of the upper airway, 1st ed edn. New York: Churchill Livingstone; 1995.

3. Bennett AK, Mills SE, Wick MR. Salivary-type neoplasms of the breast and lung. Semin Diagn Pathol. 2003;20(4):279-304. https://doi.org/10.1053/j. semdp.2003.09.001.

4. Moukarbel RV, Goldstein DP, O'Sullivan B, Gullane PJ, Brown DH, Wang L, et al. Adenoid cystic carcinoma of the larynx: a 40-year experience. Head Neck. 2008:30(7):919-24. https://doi.org/10.1002/hed.20802.

5. Bernhardt D, Sterzing F, Adeberg S, Herfarth K, Katayama S, Foerster R, et al. Bimodality treatment of patients with pelvic adenoid cystic carcinoma with photon intensity-modulated radiotherapy plus carbon ion boost: a case series. Cancer Manag Res. 2018;10:583-8. https://doi.org/10.2147/CMAR.S14 8395.

6. Barcellini A, Gadducci A, Laliscia C, Imparato S, Vitolo V, Preda L, et al. Adenoid cystic carcinoma of Bartholin's gland: what is the best approach? Oncology. 2020;98(8):513-9. https://doi.org/10.1159/000506485.

7. Khan AJ, DiGiovanna MP, Ross DA, Sasaki CT, Carter D, Son YH, et al. Adenoid cystic carcinoma: a retrospective clinical review. Int J Cancer. 2001; 96(3):149-58. https://doi.org/10.1002/ijc.1013.

8. Gaissert HA, Mark EJ. Tracheobronchial gland tumors. Cancer Control. 2006; 13(4):286-94. https://doi.org/10.1177/107327480601300406.

9. Molina JR, Aubry MC, Lewis JE, Wampfler JA, Williams BA, Midthun DE, et al. Primary salivary gland-type lung cancer: spectrum of clinical presentation, histopathologic and prognostic factors. Cancer. 2007;110(10):2253-9. https:// doi.org/10.1002/cncr.23048.

10. Jaso J, Malhotra R. Adenoid cystic carcinoma. Arch Pathol Lab Med. 2011; 135(4):511-5. https://doi.org/10.5858/2009-0527-RS.1.

11. Levy A, Omeiri A, Fadel E, Le Pechoux C. Radiotherapy for tracheal-bronchial cystic adenoid carcinomas. Clin Oncol. 2018;30(1):39-46. https://doi.org/10.1 016/j.clon.2017.10.012

12. Gaissert HA, Grillo HC, Shadmehr MB, Wright CD, Gokhale M, Wain JC, et al. Long-term survival after resection of primary adenoid cystic and squamous cell carcinoma of the trachea and carina. Ann Thorac Surg. 2004;78(6):188996; discussion 1896-1887. https://doi.org/10.1016/j.athoracsur.2004.05.064.

13. Hogerle BA, Lasitschka F, Muley T, Bougatf N, Herfarth K, Adeberg S, et al. Primary adenoid cystic carcinoma of the trachea: clinical outcome of 38 patients after interdisciplinary treatment in a single institution. Radiat Oncol. 2019;14(1):117. https://doi.org/10.1186/s13014-019-1323-z.

14. Yang H, Yao F, Tantai J, Zhao Y, Tan Q, Zhao H. Resected tracheal adenoid cystic carcinoma: improvements in outcome at a single institution. Ann Thorac Surg. 2016;101(1):294-300. https://doi.org/10.1016/j.athoracsur.2015. 06.073 . 
15. Shadmehr MB, Farzanegan $R$, Graili P, Javaherzadeh M, Arab M, Pejhan S, et al. Primary major airway tumors; management and results. Eur J Cardiothoracic Surg. 2011;39(5):749-54. https://doi.org/10.1016/j.ejcts.2010.08.047.

16. Kanematsu T, Yohena T, Uehara T, Ushijima C, Asoh H, Yoshino I, et al. Treatment outcome of resected and nonresected primary adenoid cystic carcinoma of the lung. Ann Thoracic Cardiovasc Surg. 2002;8(2):74-7.

17. Lee JH, Jung EJ, Jeon K, Koh WJ, Suh GY, Chung MP, et al. Treatment outcomes of patients with adenoid cystic carcinoma of the airway. Lung Cancer. 2011;72(2):244-9. https://doi.org/10.1016/j.lungcan.2010.08.011.

18. Hyoung Uk J, SYS, Kim DK, Kim Y-H, Jeong S-Y, Back GM, et al. A 10-year clinical outcome of radiotherapy as an adjuvant or definitive treatment for primary tracheal adenoid cystic carcinoma. Radiat Oncol. 2017;(12):196

19. Grillo HC, Mathisen DJ. Primary tracheal tumors: treatment and results. Ann Thorac Surg. 1990;49(1):69-77. https://doi.org/10.1016/0003-4 975(90)90358-D.

20. Maziak DE, Todd TR, Keshavjee SH, Winton TL, Van Nostrand P, Pearson FG. Adenoid cystic carcinoma of the airway: thirty-two-year experience. J Thorac Cardiovasc Surg. 1996;112(6):1522-31; discussion 1531-1522. https://doi. org/10.1016/S0022-5223(96)70011-9.

21. Mornex F, Coquard R, Danhier S, Maingon P, El Husseini G, Van Houtte P. Role of radiation therapy in the treatment of primary tracheal carcinoma. Int J Radiat Oncol Biol Phys. 1998;41(2):299-305. https://doi.org/10.1016/S03 60-3016(98)00073-X.

22. Bittner N, Koh WJ, Laramore GE, Patel S, Mulligan MS, Douglas JG. Treatment of locally advanced adenoid cystic carcinoma of the trachea with neutron radiotherapy. Int J Radiat Oncol Biol Phys. 2008;72(2):410-4. https:// doi.org/10.1016/j.jijobp.2008.01.016.

23. Chen F, Huang M, Xu Y, Li T, Xie K, Zhang L, et al. Primary tracheal adenoid cystic carcinoma: adjuvant treatment outcome. Int J Clin Oncol. 2015;20(4): 686-92. https://doi.org/10.1007/s10147-014-0771-6.

24. Wang Y, Cai S, Gao S, Xue Q, Mu J, Gao Y, et al. Tracheobronchial adenoid cystic carcinoma: 50-year experience at the National Cancer Center, China. Ann Thorac Surg. 2019;108(3):873-82. https://doi.org/10.1016/j.athoracsur.2 019.03.065.

25. Verma $V$, Lin L, Simone CB 2nd. Proton beam therapy for bronchogenic adenoid cystic carcinoma: dosimetry, toxicities, and outcomes. Int J Part Ther. 2018;4(4):1-9. https://doi.org/10.14338/IJPT-17-00014.1.

26. Kubo N, Saitoh Jl, Shimada H, Shirai K, Kawamura H, Ohno T, et al. Dosimetric comparison of carbon ion and $\mathrm{X}$-ray radiotherapy for stage IIIA non-small cell lung cancer. J Radiat Res. 2016;57(5):548-54. https://doi.org/1 $0.1093 / \mathrm{jrr} / \mathrm{rrw041.}$

27. Giaddui T, Chen W, Yu J, Lin L, Simone CB 2nd, Yuan L, et al. Establishing the feasibility of the dosimetric compliance criteria of RTOG 1308: phase II randomized trial comparing overall survival after photon versus proton radiochemotherapy for inoperable stage II-IIIB NSCLC. Radiat Oncol. 2016; 11(1):66. https://doi.org/10.1186/s13014-016-0640-8.

28. Ebara T, Shimada H, Kawamura H, Shirai K, Saito J, Kawashima M, et al. Dosimetric analysis between carbon ion radiotherapy and stereotactic body radiotherapy in stage I lung cancer. Anticancer Res. 2014;34(9):5099-104.

29. Suzuki M, Kase Y, Yamaguchi H, Kanai T, Ando K. Relative biological effectiveness for cell-killing effect on various human cell lines irradiated with heavy-ion medical accelerator in Chiba (HIMAC) carbon-ion beams. Int J Radiat Oncol Biol Phys. 2000;48(1):241-50. https://doi.org/10.1016/S0360-301 6(00)00568-X.

30. Peschke P, Karger CP, Scholz M, Debus J, Huber PE. Relative biological effectiveness of carbon ions for local tumor control of a radioresistant prostate carcinoma in the rat. Int J Radiat Oncol Biol Phys. 2011;79(1):23946. https://doi.org/10.1016/j.jijrobp.2010.07.1976.

31. Jensen AD, Nikoghosyan AV, Poulakis M, Hoss $A$, Haberer $T$, Jakel $O$, et al. Combined intensity-modulated radiotherapy plus raster-scanned carbon ion boost for advanced adenoid cystic carcinoma of the head and neck results in superior locoregional control and overall survival. Cancer. 2015;121(17): 3001-9. https://doi.org/10.1002/cncr.29443.

32. Chen J, Lu JJ, Ma N, Zhao J, Chen C, Fan M, et al. Early stage non-small cell lung cancer treated with pencil beam scanning particle therapy: retrospective analysis of early results on safety and efficacy. Radiat Oncol. 2019;14(1):16. https://doi.org/10.1186/s13014-019-1216-1.

33. Scholz M, Kraft G. Track structure and the calculation of biological effects of heavy charged particles. Adv Space Res. 1996;18(1-2):5-14. https://doi.org/1 0.1016/0273-1177(95)00784-C.
34. Tsujii $H$, Kamada T. A review of update clinical results of carbon ion radiotherapy. Jpn J Clin Oncol. 2012;42(8):670-85. https://doi.org/10.1093/ jjco/hys 104 .

35. Qin M, Fu Y, Yu D, Xu S, Han M, Wang Z: Diagnosis and treatment of tracheal or bronchuotracheal adenoid cystic carcinoma. Chinese J Lung Cancer 2010, 13(6):628-631, DOI: https://doi.org/10.3779/j.issn.1009-3419.201 0.06.016.

36. Fields JN, Rigaud G, Emami BN. Primary tumors of the trachea. Results of radiation therapy. Cancer. 1989;63(12):2429-33. https://doi.org/10.1002/10970142(19890615)63:12<2429::AID-CNCR2820631210>3.0.CO;2-0

37. Aumont-le Guilcher M, Prevost B, Sunyach MP, Peiffert D, Maingon $P$, Thomas L, et al. High-dose-rate brachytherapy for non-small-cell lung carcinoma: a retrospective study of 226 patients. Int J Radiat Oncol Biol Phys. 2011;79(4):1112-6. https://doi.org/10.1016/j.jirobp.2009.12.041.

38. Carvalho Hde A, Goncalves SL, Pedreira W Jr, Gregorio MG, de Castro I, Aisen S. Irradiated volume and the risk of fatal hemoptysis in patients submitted to high dose-rate endobronchial brachytherapy. Lung Cancer. 2007;55(3):319-27. https://doi.org/10.1016/j.lungcan.2006.10.015.

39. Hara R, Itami J, Aruga T, Kozuka T, Nakajima K, Yamashita H, et al. Risk factors for massive hemoptysis after endobronchial brachytherapy in patients with tracheobronchial malignancies. Cancer. 2001;92(10):2623-7. https://doi.org/10.1002/1097-0142(20011115)92:10<2623::AID-CNCR1615>3.0. $\mathrm{CO} ; 2-\mathrm{X}$

40. Laurie $\mathrm{SA}$, Ho AL, Fury MG, Sherman E, Pfister DG. Systemic therapy in the management of metastatic or locally recurrent adenoid cystic carcinoma of the salivary glands: a systematic review. Lancet Oncol. 2011;12(8):815-24. https://doi.org/10.1016/S1470-2045(10)70245-X.

41. Tchekmedyian V, Sherman EJ, Dunn L, Tran C, Baxi S, Katabi N, et al. Phase II study of Lenvatinib in patients with progressive, recurrent or metastatic adenoid cystic carcinoma. J Clin Oncolo. 2019;37(18):1529-37. https://doi. org/10.1200/JCO.18.01859.

\section{Publisher's Note}

Springer Nature remains neutral with regard to jurisdictional claims in published maps and institutional affiliations.
Ready to submit your research? Choose BMC and benefit from:

- fast, convenient online submission

- thorough peer review by experienced researchers in your field

- rapid publication on acceptance

- support for research data, including large and complex data types

- gold Open Access which fosters wider collaboration and increased citations

- maximum visibility for your research: over $100 \mathrm{M}$ website views per year

At BMC, research is always in progress.

Learn more biomedcentral.com/submissions 